\title{
Recent Advancements in Energy-Saving Technologies for the Metallurgical and Mining Industries
}

\author{
CONG WANG ${ }^{1,2}$ \\ 1.-College of Materials and Metallurgy, Northeastern University, Shenyang 110819, People's \\ Republic of China. 2.—e-mail: wangcas@gmail.com
}

As the society-level entity actively promoting communications for the sustainable production and manufacture of minerals, metals, and materials, the TMS Energy Committee has engaged in this issue of $J O M$ world-renowned scientists to offer technical solutions and perspectives reflecting state-of-the-art advancements in process efficiency enhancement, energy consumption abatement, process emissions minimization, and alternative sources of energy implementation.

A large portion of the collected articles are dedicated to address the technological advancements and convention-defying concepts for the iron and steel industry. In the article titled "Methods for Calculating Energy Requirements for Processes in Which a Reactant Is Also a Fuel-Need for Standardization," H.Y. Sohn and Miguel Olivas-Martinez (University of Utah, USA) emphasized the significance of selecting a standard approach when dealing with calculations for energy requirements by illustrating the novel flash ironmaking process. The group led by S. Seetharaman at the University of Warwick (U.K.) and Carnegie Mellon University (USA), in their article titled "Phosphorus, the Noose of Sustainability and Renewability in Steelmaking" by Mohammed A. Tayeb, Stephen Spooner, and Seetharaman Sridhar, touched on the impurity management aspect, in particular, phosphorous control measures obtained from lab-scale experiments, to offer possible solutions for energy savings and, eventually, terminal profitability for the steelmaking industry. On another dimension, in the article "Energy and Resource Saving of Steelmaking Process: Utilization of Innovative Multi-Phase Flux during Dephosphorization Process" by Hiroyuki Matssura, Tasuku Hamano, Ming Zhong, Xu Gao, Xiao Yang, and Fumitaka Tsukihashi, Tsukihashi's team (University of Tokyo, Japan) employed the "multi-phase flux" concept to enhance the utilization of major fluxing agents, such as $\mathrm{CaO}$, for a highly efficient dephosphorization process during the steelmaking process. The efforts launched by
Baek Lee and I. Sohn (Yonsei University, Korea) in their article titled "A Review of Innovative Energy Savings Technology for the Electric Arc Furnace" examined the energy innovations for the electric arc furnace routes and suggested that the utilization of waste heat of the slags could offer the potential for minimizing energy consumption. Furthermore, they postulated that the conversion of thermal energy to chemical energy to form $\mathrm{CO}$ could be a decent option for off-gas utilization. Downstream processes, such as the continuous casting step, as articulated by L. Zhou and W. Wang (Central South University, China) in their article "Energy Saving Through the Controlling of Initial Solidification during Continuous Casting," were also shown to be potent in minimizing the extra post-cast energy requirement, via proper treatment in mold flux, cooling conditions, and fluid flow adjacent to the meniscus that are of essential importance for the initial solidification.

The aluminum industry also calls for intensive attention. Based on plant data from the powerhouse for aluminum production, the article titled "Feasibility Study of Regenerative Burners in Aluminum Holding Furnaces" by Mohamed I. Hassan and Rashid Al Kindi (Masdar Institute, UAE) investigates the feasibility of the regenerative-burners' furnaces to increase the furnace efficiency to reduce gas consumption. In her article titled "Challenges in Melt Furnace Tests," Cynthia Belt (Energy Consultant, USA) illustrated the significance of measurement as the critical component for energy management in cast houses. As far as the more upstream alumina production is concerned, the novel two-step "calcification-carbonation" technique was proposed in the article titled "CalcificationCarbonation Method for Cleaner Alumina Production and $\mathrm{CO}_{2}$ Utilization" by Guo-Zhi Lu, Ting-An Zhang, Xiao-Feng Zhu, Yan Liu, Yan-Xiu Wang, Fang-Fang Guo, Qiu-Yue Zhao, and Chao-Zhen Zheng (Northeastern University, China) to change the equilibrium structure of red mud produced from the Bayer process so that the modified red mud 
could have added value for renewed applications in other industries.

The concept of "Thio-metallurgy" was introduced by Neale R. Neelameggham, Robert E. Brown, and Brian R. Davis (Ind. LLC, USA) in the article "Energy Efficient and Low GHG Emission Thiometallurgy." The authors showcased the use of sulfur in the extraction of metals in alleviating $\mathrm{CO}_{2}$ and water vapor-GHG emissions, and they demonstrated its ability to provide a cost-effective energy material solution for a variety of metal productions, such as alkaline earth metals and titanium.

We hope the edited articles can serve as an ideal communication platform for the greater metallurgical and mining industry and invite more sparkles for the next wave pushing the energy-saving technologies frontier forward. 